\title{
A VÍDEOCONFERÊNCIA COMO UM RECURSO PARA AS AULAS DA DISCIPLINA DE LIBRAS NA EDUCAÇÃO A DISTÂNCIA
}

Lais dos Santos di Benedetto ${ }^{1}$, Denise Ivana de Paula Albuquerque ${ }^{2}$, Lívia Raposo Bardy ${ }^{1,4}$, Elisa Tomoe Moriya Schlünzen ${ }^{3}$

Universidade Estadual Paulista - UNESP, ${ }^{1}$ Programa de Pós-Graduação em Educação, ${ }^{2}$ Departamento de Educação Física, ${ }^{3}$ Departamento de Estatística, Presidente Prudente, SP. ${ }^{4}$ Universidade do Oeste Paulista - UNOESTE, Pedagogia a Distância. Fundação Dracenense de Educação e Cultura - UNIFRADA. Cursos de Licenciatura. Email: libras.lais@hotmail.com

\section{RESUMO}

A inclusão da Libras, como disciplina curricular nos cursos de graduação da Unesp, em cumprimento à Lei 10.436/2002 e ao Decreto 5.626/2005, tem o propósito de atender a legislação e contribuir na formação dos futuros professores. Essa disciplina é oferecida na modalidade semipresencial, sistematizada em três momentos: atividades a distância no Ambiente Virtual de Aprendizagem, aulas práticas em Videoconferências e atividades de formação e avaliação presenciais. $O$ objetivo deste estudo foi analisar como as aulas por Videoconferência podem favorecer a aprendizagem da prática de Libras e contribuir no processo de formação dos estudantes. A metodologia foi embasada nos pressupostos da pesquisa qualitativa. Os resultados demostraram que o uso da Videoconferência, baseada nos conceitos da Abordagem Comunicativa de Brow (1994), na qual o aprendizado de uma língua ocorre na interação entre estudantes e com o professor, foi uma importante estratégia para as aulas e tem refletido positivamente na aprendizagem dos estudantes.

Palavras-Chave: Língua de sinais, formação de professores, Vídeoconferência, interação.

\section{VIDEOCONFERENCING AS A RESOURCE FOR LESSONS POUNDS DISCIPLINE IN DISTANCE EDUCATION}

\begin{abstract}
The inclusion of Libras, as a curricular subject in graduation courses at Unesp, in compliance with Law 10.436/2002 and Decree 5,626/2005, has the purpose to meet the legislation and to contribute with the preparation of future teachers. This subject is offered in blended mode, systematized in three moments: distance activities in the Virtual Learning Environment, practical classes in Videoconferences and preparation activities and assessments in the university. The aim of this study was to analyze how the classes through Videoconference can favor the learning of Libras and how contribute to the preparation process of the students. The methodology was based on the assumptions of qualitative research. The results showed that the use of Videoconference, based on the concepts of Communicative Approach of Brow (1994), in which the learning of a language occurs in the interaction between students and the teacher, was an important strategy for the classes and have been reflected positively on student's learning.
\end{abstract}

Keywords: Sign Language, Teacher's Preparation, Videoconfence, Interaction. 


\section{INTRODUÇÃO}

A inclusão da Língua Brasileira de Sinais, Libras, como disciplina curricular nos cursos de graduação da Unesp, está relacionada ao atendimento à Lei 10.436/2002 e ao Decreto 5.626/2005, que estabeleceram dez anos para que as Instituições de Ensino Superior (IES) de todo o Brasil, se organizassem para oferecimento do ensino da Libras nos cursos de licenciatura e Fonoaudiologia.

Com o propósito de atender a legislação e, principalmente de contribuir com um processo de formação de qualidade aos futuros professores da educação básica e profissionais dos demais cursos da educação superior, a Unesp oferece desde o ano de 2012 uma disciplina de Libras por meio da modalidade semipresencial a todas as suas unidades.

Atualmente a disciplina é intitulada "Libras, Educação Especial e Inclusiva" por abordar não apenas a temática da Libras, mas também conteúdos sobre as Políticas Públicas para a educação inclusiva. Entretanto, a disciplina é mais conhecida como "disciplina de Libras". A disciplina está vinculada ao Departamento de Estatística (DEst) da Faculdade de Ciências e Tecnologia (FCT), e é composta por 60 horas de atividades teóricas e práticas, implementada no Ambiente Virtual de Aprendizagem (AVA) da plataforma Moodle, e no sistema de Videoconferência próprio da Unesp.

A Libras como disciplina curricular nos cursos de graduação da Unesp, vem ao encontro da premissa da formação dos futuros professores e profissionais para atender as expectativas que emanam do contexto educacional e social. Com o advento das Políticas Públicas para a inclusão no contexto escolar, uma perspectiva que exige ser repensada e, diz respeito à formação dos professores, que precisam estar preparados para atender os Estudantes Público-Alvo da Educação Especial (EPAEE). A formação de professores deve ser concebida como uma das componentes da mudança, em conexão estreita com outros setores e áreas de intervenção, e não como uma espécie de condição prévia da mudança [...] "a formação não se faz antes da mudança, se faz durante" (NÓVOA, 1995. p. 28).

O acesso a Libras dos futuros profissionais formados pela Unesp, deverá favorecer a comunicação com o estudante surdo. De acordo com o Decreto no 5.622/2005, a educação inclusiva pressupõe a transformação do ensino com apoio do Atendimento Educacional Especializado (AEE), e que garantirá o domínio da língua portuguesa a partir da Libras, proporcionando ao estudante surdo a possibilidade de se comunicar durante as aulas na sala de ensino regular.

No que se refere, ao oferecimento dessa disciplina na Unesp, buscou-se, por meio da Educação a Distância (EaD) e de recursos das Tecnologias Digitais de Informação e Comunicação (TDIC), ultrapassar as dimensões geográficas da universidade de modo a agregar professores e discentes das diferentes unidades, para uma formação básica na Libras. Para Azevedo (2013) a EaD torna-se uma ferramenta em potencial na forma de democratização da educação superior, uma vez que sejam considerados a igualdade, a diversidade, as necessidades individuais e as potencialidades de cada aluno no percurso individual da aprendizagem no desenvolvimento das práticas de formação além das características e o ritmo de cada aluno.

A disciplina está organizada e implementada no Ambiente Virtual de Aprendizagem (AVA) Moodle, do Portal Edutec, vinculado ao Núcleo de Educação a Distância (NEaD) da Unesp; os conteúdos e atividades foram organizados por uma equipe multidisciplinar, composta por uma professora conteudista; especialistas em EaD (Design Educacional, Webdesign), coordenadores e tutores, uma Intérprete de Libras e também a participação de uma pessoa surda.

A proposta consistiu na realização de uma disciplina que possibilitasse criar estratégias que favorecessem um ambiente de aprendizado a distância, em que todos os envolvidos estivessem habilitados para transformar-se em construtores de seu conhecimento. Assim a estratégia adotada foi utilizar a Vídeoconferência como um momento de interação, bem como de aprendizagem para a prática da Libras. 
É importante salientar que, o uso das Tecnologias Digitais de Informação e Comunicação (TDIC) na educação diz respeito ao uso de diferentes recursos e a videoconferência é um deles.

A responsabilidade sobre o aperfeiçoamento da comunicação em Libras com os estudantes das diferentes unidades da Unesp, é através das Videoconferências. As responsáveis pela organização das aulas com esse recurso é a Design Educacional e a Intérprete de Libras.

É nesse cenário que este estudo se instala, além de elencar como objetivo a análise de como as aulas por Videoconferência podem favorecer a aprendizagem da prática de Libras e contribuir no processo de formação dos estudantes.

\section{METODOLOGIA}

Este estudo está vinculado ao projeto de pesquisa: Implementação da Disciplina de Libras em EaD na Unesp, da linha de pesquisa Conteúdos e Didática de Libras e Educação a Distância do Grupo de Pesquisa Ambientes Potencializadores para a Inclusão (API), cadastro no comitê de ética: 10206912.2.0000.5402. Este estudo foi embasado pelos princípios da pesquisa descritiva, com a técnica da observação sistemática, para Gil (1996) é realizada em condições controladas para responder aos propósitos preestabelecidos no estudo. Os dados foram levantados nas intervenções durantes as VCs. Segundo André (1983, p. 66) a análise qualitativa pretende "apreender o caráter multidimensional dos fenômenos em sua manifestação natural, bem como captar os diferentes significados de uma experiência vivida, auxiliando a compreensão do indivíduo no seu contexto".

\section{RESULTADOS}

A disciplina está sendo oferecida em diferentes unidades da Unesp, com 4 edições, foi sistematizada em três momentos: atividades a distância (on-line) no Ambiente Virtual de Aprendizagem, atividades práticas em Videoconferências e atividades de formação em dois encontros presenciais, além do momento de avaliação final que é realizado de maneira presencial.

A Figura abaixo representa as unidades da Unesp que ofereceram a disciplina.

Figura 1: Abrangência da Disciplina de Libras na Unesp

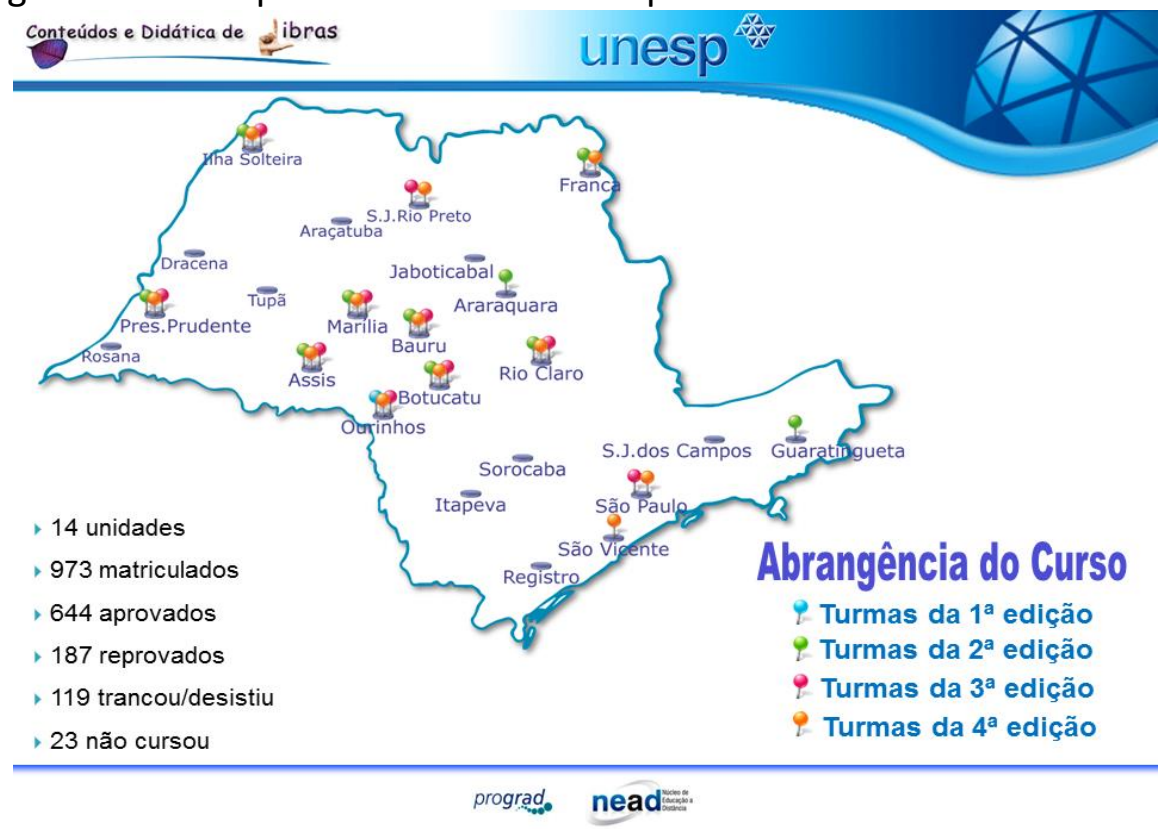

Fonte: Relatório da Disciplina de Libras

Os dados do Mapa, na figura acima, apresentam as unidades nas quais a disciplina foi oferecida, caracterizando uma rede na perspectiva multicampus. 
As aulas práticas de Libras foram realizadas por meio do sistema de Videoconferência da Unesp, que consta com a Cisco e Jabber. O primeiro funciona como uma videoconferência comum, entretanto, possui áudio de alta qualidade e vídeo de alta definição através de uma rede de IP (Protocolo da Internet) segura, para acessá-lo é necessário entrar em uma das salas disponíveis ou fazer ligação ponto-a-ponto, várias unidades podem se conectar nessa sala virtual simultaneamente. Já o segundo é um software, em que é preciso um login e senha para acessá-lo e realizar uma videoconferência, contudo, sua qualidade é inferior ao da Cisco.

Na disciplina de Libras, nas aulas por Videoconferência os conteúdos são organizados de acordo com as agendas do AVA. É importante salientar que os temas trabalhados nas videoconferências são os mesmo disponíveis nas videoaulas no AVA.

NA 1ㅁ Videoconferência estuda-se o alfabeto manual, os numerais e como utilizá-los em diferentes contextos, além dos cumprimentos e maneiras corretas de abordar pessoas surdas ou com deficiência auditiva. Discute-se sobre os cumprimentos e as perguntas frequentes que os surdos realizam ao fazer amizade, também é ensinado sinais sobre família e pessoas e, possíveis contextos sobre esses temas. Além dos temas que exploram esses vocabulários, ensina-se pronomes e advérbios, e se explora a utilização a sintaxe da Libras. Logo eles já são desafiados a usarem o alfabeto manual para soletrarem palavras para seus colegas interpretarem. Em seguida, a intérprete trabalha com os sinais de cumprimentos através da datilologia e logo após, dá continuidade com o conteúdo somente em Libras. As demais Videoconferências já podem ser trabalhadas apenas em Libras.

A 2a videoconferência aborda temas de escolarização e possíveis contextos, além de situações vivenciadas no ambiente escolar. Acredita-se que este tema seja de extrema relevância, uma vez que a maioria dos estudantes, são de cursos de licenciatura e, para tanto, necessitam conhecer e dominar vocabulários desse contexto, em que certamente vão utilizar futuramente em seus cotidianos.

Na 3ạ Videoconferência são explorados temas sobre profissões e trânsito, somando-se aos conteúdos anteriores e, desta forma, realizando diálogos ainda mais interessantes. Esses temas permeiam a vida das famílias e escolhas futuras dos estudantes surdos, desta forma, se torna um conteúdo indispensável àqueles que precisarão lidar com essas questões em sala de aula.

A 4ạ e última Videoconferência, a coordenação da disciplina convida um surdo para dialogar com os discentes, o que torna o processo de aprendizagem da Libras ainda mais interessante e contextualizado. Nesta Videoconferência, além de explorar os conteúdos anteriores que são cumulativos, ainda explora sinais de países, estados e natureza/clima, em que os estudantes dialogam diretamente com o surdo convidado.

Em todas as Videoconferências, a intérprete dialoga e propõe diálogos com os estudantes por meio da Libras e realiza atividades de fixação e contextualizada para que os estudantes possam explorar seus conhecimentos uns com os outros. Essa Abordagem da Comunicação pretende inserir os estudantes a uma imersão direta na língua, não permitindo o uso da língua materna, para que assim, os estudantes comecem a pensar em língua de sinais.

Uma importante estratégia é disponibilizar um tempo da aula para que os estudantes façam perguntas e tire dúvidas com o convidado através da Libras e sem interferência da intérprete que, só faz a mediação da língua, quando há algum tema mais específico

Cada Videoconferência tem duração de quatro horas, e a metodologia de trabalho segue uma linha com características lúdicas, de modo a envolver todos os estudantes nas atividades, interagir uns com os outros e com a intérprete, dessa forma é possível observar uma mudança de comportamento dos estudantes da 1a para a 4ạ Videoconferência.

No decorrer das Videoconferências, os conteúdos são inseridos conforme os estudantes têm acesso às videoaulas de Libras. A evolução é observável, pois, os estudantes vão se familiarizando progressivamente com a língua de sinais, até que na última Videoconferência, os 
estudantes já conversam em Libras uns com os outros e com o convidado surdo sem nenhuma interferência da intérprete.

\section{DISCUSSÃO}

A Libras é uma língua de modalidade espaço-visual e, uma de suas características, é a linguagem corporal, através das expressões faciais e corporais que fazem parte de sua formação linguística. Como a língua portuguesa, é oral-auditiva, a maioria dos ouvintes não estão acostumados a se expressarem corporalmente com frequência, uma vez em que sua língua materna não exige isso, o que é o contrário da Libras, conforme a Lei 10.436 de 2002 estabelece que a Libras é uma forma de comunicação e expressão, cujo sistema linguístico é de natureza visual-motora e que possui estrutura gramatical própria (BRASIL, 2002).

Portanto, é fundamental utilizar técnicas de expressões para que eles se familiarizem um pouco com as peculiaridades da nova língua. Daí a importância da interação, que na EaD pode ser potencializada com aulas por Videoconferência.

A linguagem se torna um recurso essencial para o desenvolvimento da interação, pois ela é o meio pelo qual as relações se estabelecem no ambiente virtual. Essa modalidade educativa "possui, além de autoridade formativa, uma potencialidade ímpar para a promoção de experiências significativas e inventivas no trato das tecnologias e do conjunto de conhecimentos que elas abrangem" (LOPES, 2010, p. 289).

A inserção das Videoconferências na disciplina refletiu positivamente na aprendizagem dos estudantes. Muitos relataram que a interação e conversação com a intérprete e entre os próprios colegas favoreceu um maior domínio na língua. As Videoconferências emprestam os conceitos da aprendizagem permeada na Abordagem Comunicativa de Brow (1994), em que acredita que o aprendizado de uma língua ocorre na interação de estudantes uns com os outros e com o professor, em comunicação que ilustram situações possíveis e reais, sem conter o foco na gramática e monitorada o tempo todo.

Desta forma, os resultados mostram que esses estudantes, que serão futuros professores, podem ter condições de se comunicar com seus possíveis futuros estudantes surdos através da Libras, podendo, minimamente, atuar em um contexto de inclusão. É preciso destacar que a disciplina apresentada não tem a pretensão de formar especialistas como intérpretes ou professores de Libras, o intuito é proporcionar conhecimento que possibilitem uma comunicação cotidiana dos futuros docentes com os surdos no contexto escolar e sobre seus preceitos.

Pode-se concluir que a aula por Videoconferência foi um importante recurso para o processo ensino e aprendizagem da Libras. Nessa perspectiva está sendo possível oferecer aos estudantes da Unesp uma formação pautada nos princípios contemporâneos da Educação.

\section{CONCLUSÃO}

A partir da atual legislação e na perspectiva das políticas públicas, a inclusão educacional das pessoas com surdez ou com deficiência auditiva, deve garantir oportunidades de aprendizagem dos conteúdos do currículo e, com qualidade. Assim, é indispensável que os professores e profissionais da área educacional, tenham uma formação fundamentada nos pressupostos das diretrizes para a área, bem como, tenham conhecimentos para atender as pessoas com deficiências em qualquer contexto.

Nesse sentido é valorosa a iniciativa da Pró Reitoria de Graduação da Unesp, em implementar a disciplina de Libras na matriz curricular dos cursos de Licenciatura, por meio da modalidade a distância, não atendendo apenas a legislação, mas buscando fundamentar uma formação desses futuros professores, em consonância com as exigências da sociedade contemporânea, uma vez que a disciplina compreende os estudos e reflexões sobre a Educação Especial e Inclusiva. 


\section{REFERÊNCIAS}

ANDRÉ, M. E. D. A. Texto, contexto e significado: algumas questões na análise de dados qualitativos. Cadernos de Pesquisa, (45): 66-71, 1983. https://doi.org/10.15603/21761043/el.v16n1p151-169

AZEVEDO, A. B. Aprendizagem na EaD: contribuições e desafios. Educação \& Linguagem, São Paulo, v. 16, n. 1, p. 151-169, jan./jul. 2013.

BRASIL. Decreto no 5.625, de 22 de dezembro de 2005. Regulamenta a Lei $n^{\circ} 10.436$, de 24 de abril de 2002, que dispõe sobre a Língua Brasileira de Sinais - Libras, e o art. 18 da Lei no 10.098, de 19 de dezembro de 2000. Diário Oficial da União, Brasília, 23 dez. 2005.

BRASIL. Lei no 10.436, de 24 de abril de 2002. Dispõe sobre a Língua Brasileira de Sinais - Libras e dá outras providências. Diário Oficial da União, Brasília, 25 abr. 2002.

BROWN, H. D. (1994). Teaching by principles: An interactive approach to language pedagogy. Englewood Cliffs, New Jersey: Prentice Hall Regents.

DORNELLES, R. J. A utilização de tecnologias de Internet na educação a distância: o caso de uma disciplina de graduação da Escola de Administração da Universidade Federal do Rio Grande do Sul. Porto Alegre: UFRGS, 2001. Dissertação de Mestrado em Administração.

GIL, A. Como elaborar projetos. São Paulo. Atlas, 1996.

LOPES, J. P. Educação a distância e a constituição da docência: formação para ou com as tecnologias?. Inter-Ação, v. 35, n. 2, p. 275-292, jul./dez. 2010. https://doi.org/10.5216/ia.v35i2.12665

NÓVOA, A. Profissão professor. NÓVOA, A (Org.) Profissão professor. Porto: Porto Editora, 1999. PALLOFF, R. M.; PRATT, K. $O$ aluno virtual: um guia para trabalhar com alunos on-line. Porto Alegre: Artmed, 2004.

QUADROS, R. M. Inclusão de surdos: uma das peças do quebra cabeça da educação. In: PINHO, S. Z. de (Coord.). Caderno de formação: formação de professores: Bloco 02: Didática dos conteúdos. São Paulo: Cultura Acadêmica, 2012. p. 75-78. (Conteúdos e Didática de Libras).

SCHLÜNZEN, E. T. M. Mudanças nas Práticas Pedagógicas do Professor: criando um ambiente construcionista contextualizado e significativo para crianças com necessidades especiais físicas. São Paulo, 2000. Tese (Doutorado em Educação: Currículo). Pontifícia Universidade Católica de São Paulo (PUC_SP). 